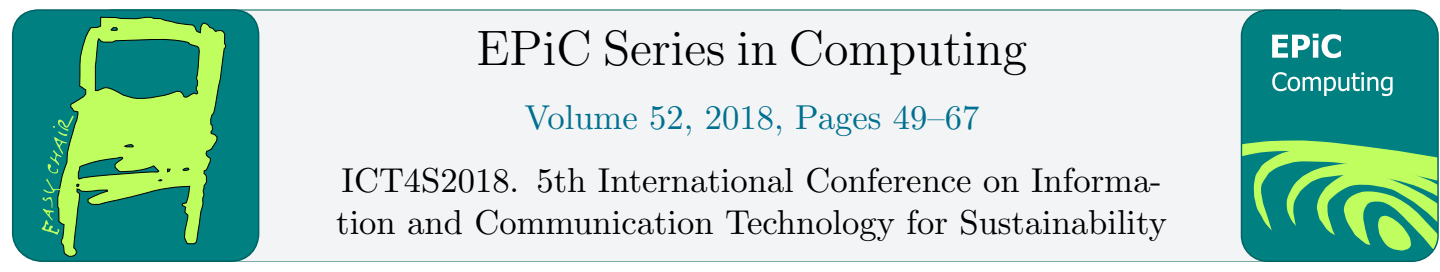

\title{
ICT for Sustainable Last-Mile Logistics: Data, People and Parcels.
}

\author{
Oliver Bates ${ }^{1}$, Adrian Friday ${ }^{1}$, Julian Allen ${ }^{2}$, Fraser McLeod ${ }^{3}$, \\ Tom Cherrett ${ }^{3}$, Sarah Wise ${ }^{4}$, Maja Piecyk ${ }^{2}$, Marzena Piotrowska ${ }^{2}$, \\ Tolga Bektas ${ }^{3}$, Thuba Nguyen ${ }^{3}$ \\ 1 Lancaster University, UK, \{o.bates,a.friday\}@lancaster.ac.uk \\ 2 University of Westminster, UK, \{allenj,m.piecyk,m.piotrowsk\}@westminster.ac.uk \\ 3 University of Southampton, UK, \{f.n.mcleod,t.j.cherrett,t.bektas,thuba.nguyen\}@soton.ac.uk \\ 4 University College London, UK, s.wise@ucl.ac.uk
}

\begin{abstract}
In this paper we present a vision of how ICT can be leveraged to help combat the impact on pollution, congestion and carbon emissions contributed by the parcel delivery sector. This is timely given annual growth in parcel deliveries, especially same-day deliveries, and the need to inform initiatives to clean up our cities such as the sales ban on new petrol and diesel vehicles in the UK by 2040. Our insights are informed by research on parcel logistics in Central London, leveraging a data set of parcel manifests spanning 6 months. To understand the impact of growing e-commerce trends on parcel deliveries we provide a mixed methods case study leveraging data-driven analysis and qualitative fieldwork to demonstrate how ICT can uncover the impact of parcel deliveries on delivery drivers and their delivery rounds during seasonal deliveries (or "the silly season"). We finish by discussing key opportunities for intervention and further research in ICT4S and co-created Smart Cities, connecting our findings with existing research and data as a call to the ICT4S community to help tackle the growth in carbon emissions, pollution and congestion linked to parcel deliveries.
\end{abstract}

Keywords - sustainability, logistics, parcel sector, parcel demand, last mile logistics, stakeholder engagement, case study, smart cities, policy makers, decision support, kerb side optimisation, air pollution

\section{Introduction}

The amount of goods delivered in our urban environments is increasing, in part due to a rapid growth in e-commerce and online shopping, driving up the number of home deliveries made. In 2015, an estimated 1 billion parcels were delivered across the UK with annual growth at around $15.7 \%$ [28]. In the UK alone, e-commerce and online shopping is a $£ 50$ billion per year industry, contributing $14.2 \%$ of all retail spending in July 2016, with an annual growth of $17.3 \%$ in 2016 [41]. This growth is forecast to continue at 10-12\% per annum till 2021 [36]. 
Parcels are transported using freight transport vehicles such as trucks, lorries and vans, making up around $16 \%$ of total road vehicle activity in urban environments in the UK [3]. Light goods vehicles (LGVs) ${ }^{1}$ continue a trend of growth (up $4 \%$ in 2015 from 2014), contributing $13 \%$ of the UK's transport emissions in 2014 [16], rising to 15\% in 2015, with 2015 being the largest growth year in LGV since the 1980s [17]. Last-mile freight traffic has implications for environmental sustainability due to increased congestion, increased carbon emissions and increased pollution. Lorries and vans perform $30 \%$ of their activities in urban areas, contributing significantly to congestion and urban air pollution resulting in 13.3 million tonnes of carbon dioxide $\left(\mathrm{CO}_{2}\right)$ equivalent emissions in 2014 [60]. The Department of Transport recorded that in 2014, 56,000 tonnes of carbon monoxide emissions, 63,000 tonnes of nitrogen oxides, and 2,200 tonnes of particulates (PM10) were contributed from freight transport in the UK [17]. These environmental issues are likely to continue to worsen as traffic and congestion grows in cities such as central London, where it is predicted that congestion will grow by $60 \%$ by 2030, with a $20 \%$ growth in the amount of vans contributing to congestion [54].

The phrase "last mile" refers to the final stages of transportation in the logistics network. In the context of this paper, last mile parcel deliveries are used to described the final journey made by a parcel between the local depot and the end recipient in the urban logistics network. A shift towards online shopping and convenient 'one-click' access to on-demand services and shopping combined with low or even zero cost delivery services is accelerating the demand placed on last mile logistics networks and carriers [3, 44]. These low cost, loss leading and 'apparently free' deliveries squeeze margins across the logistics sector $[55,18,33,37]$ as the industry competes for market share [2, 14], making investment in workers [39, 58] and more sustainable alternatives difficult.

Sustainable transport and logistics is proclaimed as a key area in which sustainable intervention can have the greatest impact in terms of enabling more sustainable trajectories [59, 25]. One major barrier in urban and last mile logistics is supporting new policies that promote more sustainable parcel deliveries due to an urban goods sector that has remained indifferent to urban structures, promotes inefficient policies and can be slow to move when provisioning required resources $[15,20]$. Using a case study of last mile logistics we present a vision of where sustainable ICT can lead to smarter policy making, and improved round scheduling, urban planning, and collaboration to promote sustainability. Our vision is underpinned by a proposal for an ICT platform to enable smart and sustainable last mile logistics that provides a number of opportunities for computing and ICT research to engage in this important and under supported domain.

\section{Related Work}

The rapid growth in e-commerce is contributing to increased numbers of delivery vans in urban areas [41]. This is heightened during busy sales periods such as Black Friday (late November) and the run up to Christmas [13], where an analysis of national parcel carriers (excluding Amazon and DHL) indicated that October to December was the busiest period with some 439 million parcels delivered to homes across the UK [40]. Van traffic is exacerbated by the highly competitive nature of the parcel sector with many independent businesses operating in an 'everyone-delivers-everywhere' environment [10]. This is a major contributing factor to van traffic growing faster than car traffic, with van traffic accounted for $14 \%$ of all UK motor vehicle traffic in 2014 [17].

\footnotetext{
${ }^{1} \mathrm{LGVs}$ are the primary delivery vehicle in the UK.
} 
To help handle the growth in parcel demand and lower the number of vehicles on the roads, more optimal delivery models for peak periods have been proposed (e.g. [21]). Greasley et al. offer a solution that favours timed deliveries over non-timed deliveries. Whilst their model demonstrates how a 'hub and spoke' model can be used to prioritise timed deliveries optimally, their assumptions do not capture the complexity in the final stages of a delivery where the driver successfully finds a parking location, navigates from the parking location to the delivery address and locates the final delivery destination of the parcel within a building. This last step can be particularly complex in built up urban environments where parking is limited, dense urban buildings are harder to navigate, and buildings are multipurpose and multistory $[3,2,5]$.

To help evaluate less environmentally harmful options in last mile deliveries, optimisation research has developed measures to establish the break-even scenario in the last mile, comparing customers picking up their goods versus delivery of goods to customer homes [8]. 'Unattended delivery' where logistics workers drop off goods in secure lockers to help reduce the financial and environmental cost of last mile deliveries have also been proposed [45]. Others have considered the environmental cost of home deliveries and the last mile in more detail, demonstrating that van based home deliveries are less carbon intensive than low yield shopping trips [19] and how changes in home delivery can support alternative fuelled vehicles [56]. Recent work has also looking into the viability of alternative vehicles in the last mile such as cargo cycles [22] and electric vehicles [38]. These simulations and optimisations can be somewhat more difficult to deliver in reality due, in part, to the complex socio-technical systems and relationships that exist in last mile logistics [6], including non-standard parcels, difficulties finding parking locations, and navigating between and inside of multi-purpose buildings in cities [5]. The most challenging problems are often faced in the last 100 meters of a delivery.

In view of growth trends and the complexity in the last 100 meters, the use of and demand for kerbside parking and unloading places is of increasing interest and importance both to local authorities and to parcel carriers. Local authorities have the responsibility for managing and controlling how kerbside space is used (e.g. deciding on parking and unloading restrictions), while carriers have a direct interest in where they can stop to make their deliveries as quickly as possible without incurring penalties for illegal parking (UPS incurred $\$ 17 \mathrm{~m}$ in parking fines from their vehicles operating in New York, USA in 2016 [30]). Recent parcel carrier surveys have shown that more than half of their round time can be spent with drivers walking whilst their vehicles are parked by the roadside [1] highlighting the need for suitable places from which to unload and make deliveries. In response to growing pressures on kerbside space, recent developments have included the concepts of 'virtual loading bays', where operators can pay for timeslots to unload on restricted kerb space [43], and 'shared drop zones', where dedicated kerbside staff make 'last 500m' deliveries on behalf of operators [26]; however, both involve added costs for carriers. As Bates et al. highlight, understanding how drivers operate, use the kerbside and maintain relationships with customers is another part of the socio-technical puzzle that can help promote more sustainable last mile logistics $[6,5]$.

Logistics and transportation are case studies that are important to consider in the design of smart and sustainable cities [31]. In the smart city research encourages municipalities to consider rebound effects [46] and the the practices of citizens and workers [24, 47] in order to develop socio-technical solutions that work for the many and maintains a sustainable trajectory. To help support this in design, it is important to perform contextual design projects to understand how ICT is currently used and how it can be integrated effectively to support the governance of 'Smart Sustainable Cit[ies]' [32]. Data-driven analytics (e.g. Spatial Analytics [49, 34]) can be used to develop data driven models, decision support tools [11, 50], counter factual futures and scenarios that are useful tools in presenting information to policy makers (cf. [4, 51]). Solutions 
that look to encourage sustainable transformation must be sensitive to data-driven approaches where users and decision makers can 'blinded by the data' and that transparency, context and reflection is important when using data-driven approaches in sustainability [61].

Current methods for authorities and local municipalities for understanding logistics trends in the city are labour and time intensive, requiring manual surveys to provide a detailed analysis of a very small geographical area or kerbside. Yet, parcel carriers increasingly collect data to measure the performance of their fleet and workers via fleet telemetry systems and handheld terminals. This data provides a rich source of information on delivery volumes to specific locations (e.g. streets, postcode areas, individual buildings) and about the vehicle rounds undertaken to service them. We argue that this information could be highly influential in assessing parcel carriers' contribution to traffic and their needs for kerbside space, potentially assisting with urban planning and policy setting. Furthermore, research has already suggested that certain types of land use receive substantial flows of parcel traffic: a study of a major office block in central London found that more than $40 \%$ of all goods vehicle deliveries were associated with parcel and mail flows [9]. This data could help urban planners to unpack the link between different types of land use (e.g. offices, domestic residencies, commercial premises, public sector organisations) and how these contribute to the demand for parcel delivery, even informing where new delivery areas might be best located.

\section{Methods and Data}

Our observations and subsequent platform design are grounded in a mixture of formal and informal workshops, meetings, and ethnographic field work with major UK parcel carriers operating in central London between April 2016 and November 2017 as part of the Freight Traffic Control (FTC2050) research project ${ }^{2}$. Vehicle manifest data was obtained for all lastmile deliveries and collections from our partners in central London, operating mainly in the W1, WC1, WC2 and EC1-4 postcode areas between $1^{\text {st }}$ October 2016 and $7^{\text {th }}$ February 2017. Approximately $90 \%$ of the work was business-to-consumer (B2C) related across a mixed land use profile including retail, commerce and domestic customers. A total of 396 unique shippers of goods (i.e. consignors) were observed in the data with major fashion and general retailers generating the most activity and an online seller of travel tickets generating the greatest number $(\sim 110,000)$ of records. The data included parcel barcodes, delivery addresses, manifest ID numbers, driver ID numbers and various temporal information detailing when the barcode was scanned, along with associated event types which drivers selected from a set of pre-defined options (e.g. 'collection', 'delivered', 'delivery failed'). The entire database comprised 843,696 records with each record usually corresponding to a delivery or collection attempt. An individual consignment could have more than one record associated with it due to a failed delivery attempt and a repeated attempt the following day. In the most extreme case, 29 delivery attempts were made for one parcel with the average being 1.3, and 2.4 delivery attempts per parcel where the first attempt failed.

For the detailed spatial and temporal analyses, we chose to focus on a smaller study area based around Oxford Street (Figure 1) during the intense activity on the run up to Christmas (October until December 2016). This area is of particular interest for London's West End Partnership: a group of stakeholders including Transport for London (TfL), the Mayor of London and other city authorities and business associations who have a shared vision for Oxford Street to become the 'best outdoor shopping place in the world' [57]. The area is approximately

${ }^{2}$ FTC2050, www.ftc2050.com, accessed Nov. 2017. 
$1.3 \mathrm{~km}$ along the topmost edge (Seymour Street, A5204) by $400 \mathrm{~m}$ along the rightmost edge (Regent Street). Despite this area being quite small $\left(\tilde{0} .5 \mathrm{~km}^{2}\right)$, it is densely populated with a mixed land use of shops, offices and private addresses containing 1,172 distinct postcodes. For spatial analyses, heat maps were generated using GIS software (QGIS) based on latitude and longitudes obtained for each postcode. These enabled the numbers of parcels destined for particular postcodes to be displayed, with a radius of $50 \mathrm{~m}$ being drawn around each point to illustrate where overlaps in delivery locations occurred.

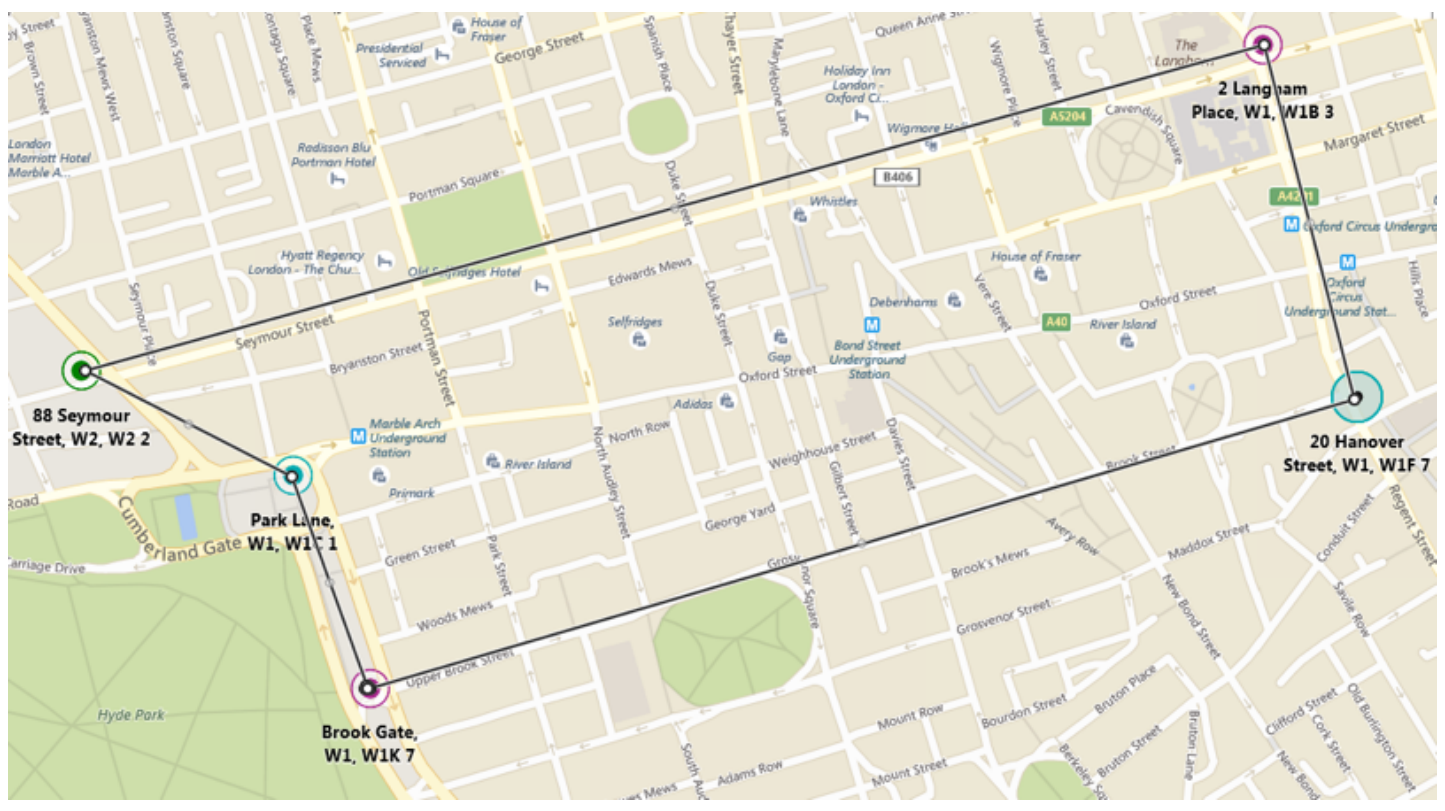

Figure 1: Overview of the Oxford Street study area (Map source: Bing Maps)

The Oxford Street study area represents around $2 \%$ of the overall dataset and, as data were extracted by matching to a full postcode, records with missing, partial or malformed postcodes were not included in the analysis. Further records could have been obtained by trying to resolve individual addresses but this was not done for data protection reasons. The clean records comprised around $65 \%$ of the total dataset and therefore represented only a sample of the full activity in the area.

While we recognise that this dataset represented only a small fraction of total urban freight activity: the parcels and mail sector accounts for around $10 \%$ of all UK vans used for work purposes and the parcel carrier had an approximate $5 \%$ share of the national parcels market [48]. Our sample is also particularly informative, since last-mile deliveries of parcels and mail by vans is largely concentrated in urban areas, and a survey on Regent Street in central London found that $21 \%$ of all motorised goods vehicles observed were parcel carriers and couriers [53].

Our analyses and results provide an indication of how such data can be harnessed to provide data which complements other freight data sources (e.g. roadside surveys) from which to build up the bigger picture of total urban freight activity which TfL and other city authorities can make use of in their planning. As such data are routinely collected by carriers, analyses are far more cost effective than manual surveys conducted by the roadside or in-vehicle; on the other hand, manual surveys can capture additional information such as parking locations used and duration of stay and may also cover other types of goods delivery or servicing activity. 


\section{Case Study: Focusing on last-mile Freight Logistics}

From a high level perspective, freight traffic is dictated by how, where and when logistics companies pick up and deliver parcels demanded by their customers. These customers (e.g. consumer/domestic, business) require parcels to get from location A to location B (e.g. a domestic or business address). A contract is agreed with a logistics company by the customer to guarantee a delivery or collection of a parcel from sender to recipient. These contracts are known as either business-to-consumer (B2C) or business-to-business (B2B) dependant on the sender and recipient. The parcel is typically collected from the sender and transported to a local depot, where it is sorted and sent out through a national logistics network to a depot local to the delivery address, and from there is transported over the last mile to the recipient.

At any depot the parcel is sorted and loaded onto a van that moves it closer to its end location. All B2B and B2C parcels travel through a minimum of one depot between sender and recipient. Delivery drivers are responsible for picking up parcels, their sorting, and ensuring timely deliveries. The delivery driver in the last mile is required to sort and order their parcels when loading their delivery van to ensure that time sensitive deliveries are prioritised and that parcels can be retrieved when arriving at a delivery or parking location. The order in which the items are loaded into the vans is critical as this effects the delivery performance of a driver.

Logistics companies utilise unique selling points (USPs) to differentiate themselves from their competition. These USPs usually translate to service level agreements (SLAs) that impact when and where a driver has to deliver a package (e.g. guaranteed delivery before 10am, next day delivery). These USPs and SLAs impact how a driver logistics companies and their drivers can optimise these rounds (e.g. a series of SLAs might lead to the suboptimal rounds), as broken SLAs are bad for business, logistics companies are under increased pressure to deliver these priority parcels at the cost of efficiency and optimally delivery rounds.

\subsection{The "Silly Season"}

An analysis of most national parcel carriers in the financial year 2014-15 confirmed October to December as being the busiest quarter of the year for the national domestic parcels market, with some 439 million parcels delivered $[40]^{3}$. We chose this particularly intense period covering Black Friday (late November) and the run up to Christmas, to offer especially dense data covering the region of interest for further analysis.

The carrier mainly operated Monday to Saturday with no deliveries on Sundays, with the exception of the Sunday after Black Friday. Mondays were the busiest day of the week, with around 241 manifest entries per day in the Oxford Street area (Figure 2), which was due to the very high proportion (49\%) of failed deliveries on Saturdays that required subsequent delivery on the Monday. The high failure rate reflects the number of offices that are closed on Saturdays and efficiency could be improved significantly if the carrier were able to avoid making these wasted trips. Failure rates during the week ranged from $7.4 \%$ (Thursdays) to $14 \%$ (Mondays) and, in comparison, IMRG [27] estimated that $13 \%-14 \%$ of all online shopping deliveries in the UK arrive either late or when the customer is not at home but in the case of tracked services, B2C failure rates were observed to be much lower, at 2\%-3\% [29]. Averaging over all days, there were 139 successful deliveries, 24 failed or carried forward deliveries and 7.4 collections per day within the Oxford Street data, with the actual activity for the carrier estimated to be around 1.5 times greater, given the sample size of recognisable delivery points ( $65 \%$ of the sample).

\footnotetext{
${ }^{3}$ Ofcom Analysis excludes Amazon and DHL.
} 


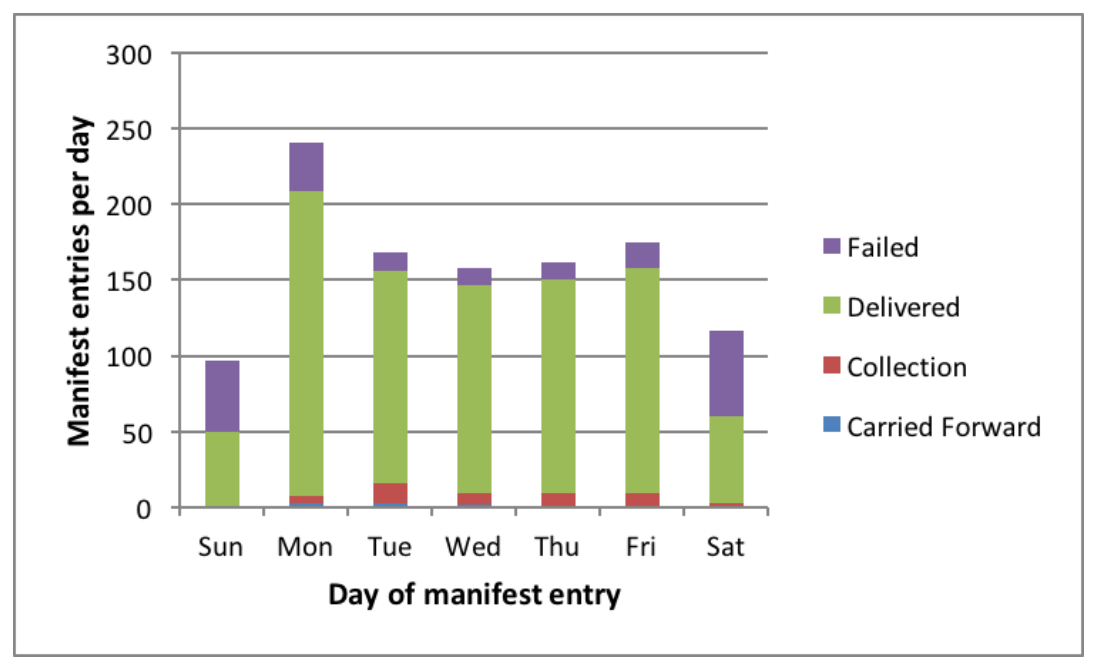

Figure 2: Number of manifest entries by day of week (Oxford Street area)

\subsection{Temporal variation in deliveries}

The numbers of deliveries made each day in the Oxford Street area was highly variable with a number of peaks where over 250 deliveries were made: Monday $3^{\text {rd }}$ October $(n=358)$, Monday $10^{\text {th }}$ October $(n=312)$, Monday $24^{\text {th }}$ October $(n=274)$, Tuesday $29^{\text {th }}$ November $(n=329)$ and Monday $12^{t h}$ December $(n=276)$. It is suspected that Monday $28^{t h}$ November would also have been a peak day; however, data were not available due to a system fault. The peaks in November and December were expected due to their proximity to the Black Friday sales and to Christmas. Mondays were already observed to be the busiest day of the week however specific reasons for the peaks in October are not known. The data for the entire dataset (i.e. the wider central London area) showed a somewhat different picture with the greatest activity on Monday $5^{\text {th }}$ December, followed next by Monday $12^{\text {th }}$ December, but with no noticeable peaks in October. This illustrates the fact that different delivery patterns can be observed in different areas and that it may be problematic to attempt to generalise from one place to another.

The majority of on-street activity took place between $11 \mathrm{am}$ and $5 \mathrm{pm}$, peaking at $2-3 \mathrm{pm}$ (Figure 3); this mainly reflects the fact that the work necessarily takes place during the daytime when the customers based in offices can take collection of their goods. Collections took place throughout the day unlike some other carriers who prefer to leave collections until later in the day, after all deliveries have been made. Collecting throughout the day likely allows more efficient vehicle routing but may be slightly more difficult in terms of organising parcels in the back of the van. Proportionally more failed deliveries were recorded after $5 \mathrm{pm}$ likely due to customers having left their offices to go home.

\subsection{Spatial variation in delivery volumes}

Of the 1,172 postcodes in the area, 708 were found in the data and the remaining 464 postcodes received no delivery or collection. Combined deliveries and collections, including failed attempts, were mapped to reveal levels of van activity across the area (Figure 3). Of particular interest are the locations receiving the most traffic as these will likely be the places where nearby unloading places will be most needed. Such mapping may be of use both to local authorities 


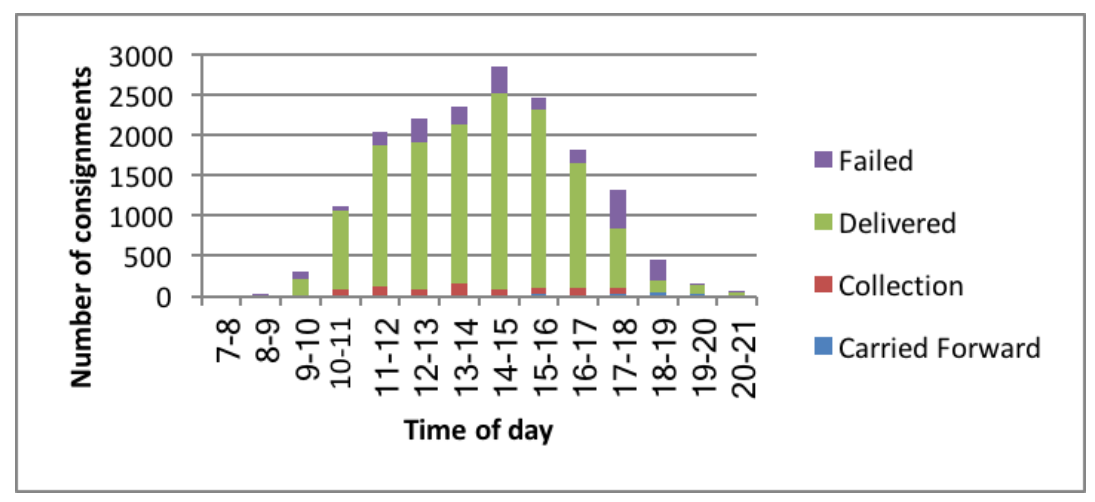

Figure 3: Number of deliveries each day (Oxford Street area)

in their planning of kerbside space utilisation and to carriers when planning vehicle schedules and routes. Parcel carrier operations typically involve considerable time spent walking between customers while the vehicle is parked by the roadside [3] and better knowledge of how to cluster groups of consignees could help them identify more optimal locations to park, as a base for the walking operations.

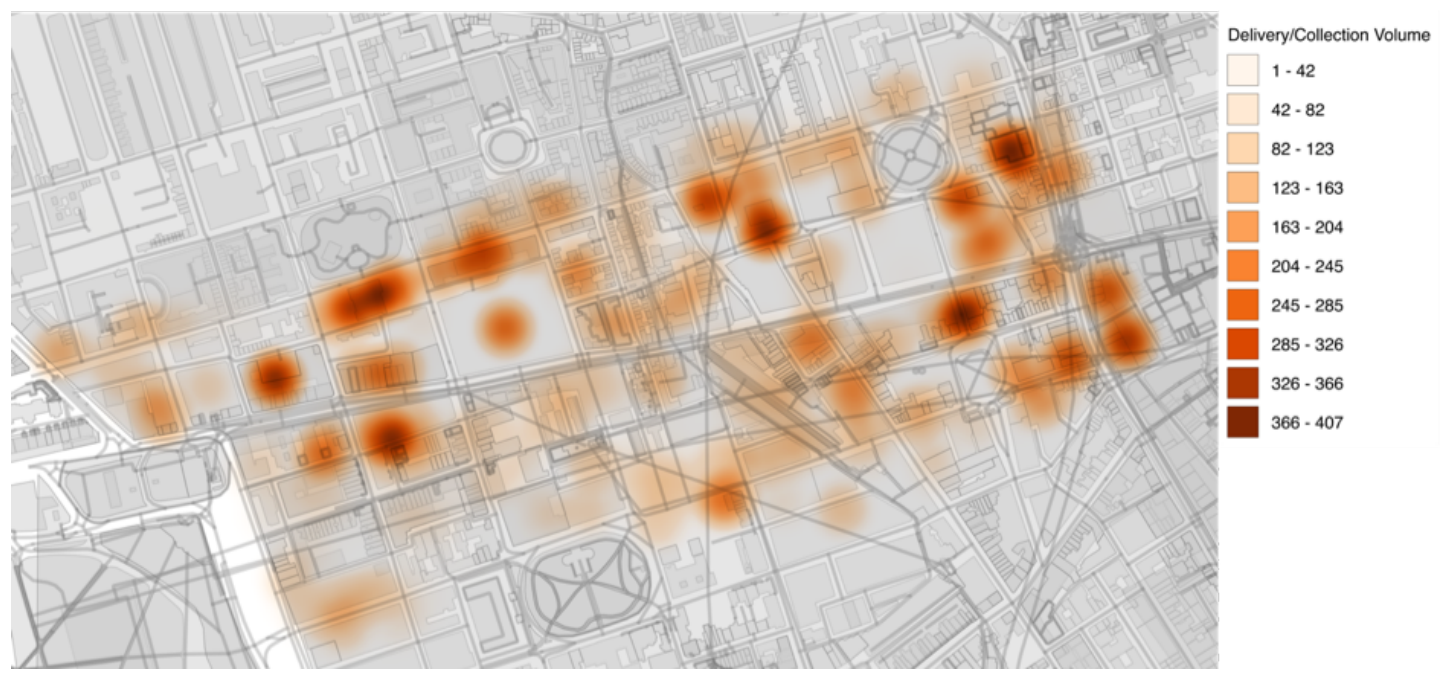

Figure 4: Total number of deliveries, collections and failures ( $1^{\text {st }}$ October 2016 to $7^{\text {th }}$ February 2017)

Most of the activity hot spots (Figure 4) appeared to be in areas of mixed land use with multi-tenanted offices, shops, restaurants and hotels, including those on Oxford Street, Regent Street and opposite Portman Square (Figure 1). Individual customer addresses generating these deliveries were not known as they had been removed from the dataset for confidentiality reasons and the records could not be reliably used to determine the extent to which personal deliveries were made to workplaces, as personal and work-related deliveries could not be easily distinguished. Such information is of interest for workplaces and transport authorities in London 
who would like to restrict such activity on the basis of the added staffing resources required for receiving personal deliveries and the added parcel carrier contribution to road and kerbside congestion [23].

Table 1: Comparison of 'top 8' and all postcode areas in terms of delivery and collection activity over the period ( $1^{\text {st }}$ October 2016 to $7^{\text {th }}$ February 2017).

\begin{tabular}{|l|rr|rr|rr|r|}
\hline \multirow{3}{*}{ Activity } & \multicolumn{6}{|c|}{$\begin{array}{c}\text { Number of occasions of activity } \\
\text { All postcodes (Top 8 postcodes) }\end{array}$} \\
\cline { 2 - 8 } & \multicolumn{2}{|c|}{ Total } & \multicolumn{2}{|c|}{ Average } & \multicolumn{2}{c|}{$\begin{array}{c}\text { Standard } \\
\text { Deviation }\end{array}$} & Maximum \\
\hline Deliveries & 14009 & $(2099)$ & 21 & $(262)$ & 44 & $(111)$ & 379 \\
\hline Collections & 753 & $(239)$ & 6 & $(30)$ & 17 & $(60)$ & 177 \\
\hline Failures & 2257 & $(294)$ & 6 & $(37)$ & 8 & $(23)$ & 84 \\
\hline All & 17019 & $(2632)$ & 24 & $(329)$ & 50 & $(50)$ & 407 \\
\hline
\end{tabular}

To illustrate the extent to which the busiest locations differed from the norm, the 'top 8' (1.1\%) postcodes, corresponding to three 'hottest' division bands used in Figure 4 (i.e. those with $>285$ deliveries, collections or failures), accounted for 13.7 times the mean activity, or $15.5 \%$ of the total activity (Table 1). In addition, the 'top 20' (2.8\%) and 'top 45' (6.4\%) postcodes accounted for $31.3 \%$ and $50 \%$ of total activity, respectively, indicating the skewed nature of the spatial distribution, with a relatively small number of places generating high levels of activity and many postcodes generating little. The high standard deviation values observed for the 'top 8' (Table 1) were largely due to the presence of one postcode that had a high number of collections (177) but relatively few deliveries (28), whereas the norm was for deliveries to outweigh collections by 18.6 to 1 .

\subsection{Express deliveries}

Also of interest were express deliveries, as they can have a significant impact on vehicle activity where they must be performed before other (non-express) deliveries to be completed on time. Such prioritisation can result in the same places being visited on the same round at different times of the day, especially where strict time window delivery deadlines are involved. The only priority consignments in the dataset were guaranteed 'next day' which accounted for around $13 \%$ of the total activity in the Oxford Street area. A combined heat map of the express and non-express deliveries (Figure 5) showed, perhaps unsurprisingly, that there was considerable overlap between the busiest locations for each (where orange and purple combine to become brown). If delivery rounds could be organised in a consistent way from day to day, in terms of the times when key locations were visited, then virtual loading bay locations and time slots could be introduced and booked by carriers to aid last-mile logistics management [43]. This could be combined with offering customers delivery time windows to match vehicle routes but at present. For many couriers, this detailed knowledge of vehicle routes is not typically known as it's up to the driver to plan their own route. It is not certain if consistent routes could be achieved due to the day-to-day variability in delivery and collection demand.

\subsection{Insights on the last mile}

This case study also suggests how the data may be used to build a freight activity profile of different types of generators of demand (e.g. offices, domestic residencies, commerce) although 


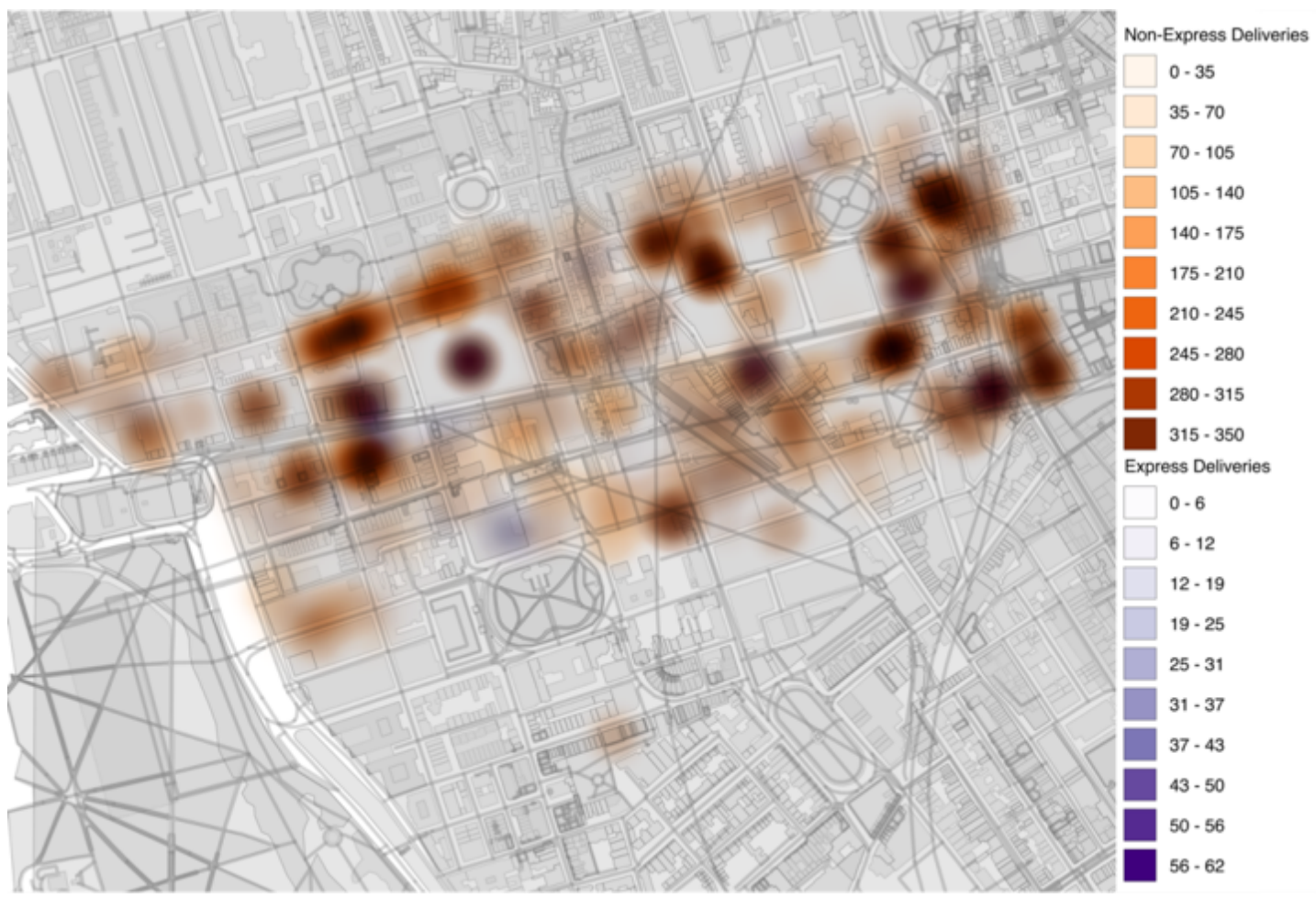

Figure 5: Spatial variation in express (next day) consignments vs. non-express consignments

it could be a difficult and time-consuming task to categorise customers, especially in multipurpose buildings, and carriers may not wish to provide such information for data protection or commercial reasons. These findings provide support for a wider consideration of how different carriers may collaborate with each other and a futuristic scenario in which live carrier data are shared with a third-party sustainable logistics platform to promote more efficient delivery schedules for more sustainable urban logistics.

\section{Discussion}

Local authorities need to rethink the way in which kerbside space is allocated and give greater consideration of urban freight user needs. Our analyses are starting to demonstrate the potential benefits of parcel carrier manifest data for investigating peaks in temporal and spatial demand and resulting vehicle activity. While our dataset represents only a small fraction of total urban freight activity it provides an indicative sample for the parcels sector to complement other data sources from which data projections may be made. As manifest data is routinely collected by carriers, analyses are far more cost effective than manual surveys conducted by the roadside or in-vehicle. We believe these data can already help us rethink the way in which we kerbside activity is thought about in our cities. 


\subsection{Rethinking the kerbside}

Parcel carriers face a highly challenging task in scheduling and performing deliveries and collections in a congested city such as London, where competition for kerb and road space is keen. At present, the vehicle routing and delivery/collection task is usually left entirely to the driver's discretion, as vehicle routing software, for example, is typically not useful as walking options are not usually considered [3].

We have observed that most kerbside space is needed between 11am and 4pm during peak activity, with $64 \%$ of deliveries or collections and $5 \%$ of the total failures occurring in this window. Our findings also show that a small proportion of locations are generating a large amount of kerbside activity. Based on the coding of our top 20 postcodes (95\% of which are primarily business use) which account for $32 \%$ of kerbside demand in our analysis, we hypothesise that a large proportion of parcels in this patch, whilst designated B2C (Business to Consumer), are being delivered to business addresses.

To help reduce environmental emissions due to parcel generation we propose that city planners with logistics companies and customers to encourage shifting peaks in time and space to reduce the kerbside pressure and parcel generation in areas, such as Oxford Street, where congestion is peak, parking and stopping locations are scarce and in patches that are particularly ripe with pedestrians. These locations can be targeted for improved access by, for example, considering the introduction of virtual loading bays or shared drop zones. Authorities may also consider ways to encourage shifting deliveries to off-peak times to reduce or spread out demand for kerbside space and reduce the impacts of parcel generation across busy areas, although there may be limited scope for this as the daytime deliveries currently observed are largely dictated by customer needs (e.g. business opening hours).

\section{2 $\quad$ B2C in the workplace}

Failed deliveries are another area where improvements may be made. In many cases it is the sender of the goods (e.g. an online retailer) who demands a certain delivery requirement of the carrier (e.g. next day) but this does not necessarily match the customer requirement (for example, the delivery address may be closed on a Saturday). Carriers could potentially reduce failed deliveries through gaining a better understanding of when their key customers are actually able to receive deliveries; however, at present, they are simply following delivery instructions and such detailed customer knowledge typically lies only with experienced drivers and not within the carrier's fleet management systems.

From the Oxford Street patch that we have focused on, we estimate approximately 90\% B2C consignments are delivered primarily to business addresses. The darkest spots in Figure 4 and Figure 5 show ${ }^{\sim} 20$ specific locations that can be targeted for deeper analysis and re-thinking in terms of kerbside and route planning. Whilst the blurring of $\mathrm{B} 2 \mathrm{~B}$ and $\mathrm{B} 2 \mathrm{C}$ parcel generation is not clear in existing surveys and data, we believe that differences between $\mathrm{B} 2 \mathrm{C}$ consignments at business addresses vs. private addresses (e.g. domestic) adds an additional dimension when considering the temporal and spatial elements of consignments (e.g. are business addresses more likely to have someone at the delivery address than private addresses during the working day, what are the implications of consumer deliveries to business addresses on public transport, would encouraging $\mathrm{B} 2 \mathrm{C}$ deliveries to the home drastically reduce kerbside events). If $\mathrm{B} 2 \mathrm{C}$ deliveries are default posted to a business address then it is possible that failures occur more often on Saturday due to businesses being closed. During seasonal peaks and rushes it is important to know when the right and wrong times are to deliver, perhaps even challenging express and priority services for $\mathrm{B} 2 \mathrm{C}$ parcel generation, especially when there is no access to a 
delivery location.

Authorities and businesses may even wish to explore new policies, such as banning personal deliveries to workplaces in order to reduce parcel carrier activity in busy urban centres; although this may simply shift 'the problem' elsewhere with unclear overall effects - suggesting a need for ongoing monitoring and reflection at a significant scale.

\subsection{Understanding the socio-technical, exploring complexity}

Identifying hot spots and peaks in parcel demand tells only part of the story: from our experience working with delivery drivers and industry partners it is clear that the deliver drivers, their decisions about where to park and walk, and how they plan their route play key roles in the effectiveness of deliveries in the last mile $[6,5]$. Understanding the actions and work practices of the drivers can help us unpack why failures occur, their decisions regarding parking, and their strategies for delivering inside multi-purpose buildings. These examples are valuable as they may yield insight that could help development of technology to help improve parking and indoor navigation for delivery drivers. Understanding the parking strategies of drivers is particularly important in the Top 20 hotspots, as these areas may require more dynamic strategies for parking vans during peak periods.

Aside from the density of Central London, another factor in the large proportion of kerbside activity relating to only 20 postcodes in Oxford Street is multi-purpose buildings. Multi-purpose buildings are particularly common in [smart] cities and urban environments with buildings composed of mixture of business and residential addresses. Understanding this relationship between urban congestion, freight, and the types and uses of buildings could even potentially help reshape how our urban spaces can be laid out to promote sustainability.

\section{A platform for sustainable last mile freight}

Our analysis has prompted the design of a platform that can help bring together expertise from different fields and disciplines that contribute to ICT4S. Figure 6 describes a three tier ICT platform that provides a vision in which data science, spatial modelling and optimisation, information systems, HCI and design, data visualisation and communication, and software engineering can enable smart and sustainable last mile logistics. This collaboration is essential in the development of a platform that can significantly reducing carbon emissions arising from logistics and transport as previously envisaged [59, 25]. This platform draws parallels with the digital taxonomy developed by Townsend, looking to drive transformation through assessment (Raw Data \& Context); innovation (Models \& Analytics); and, adoption and driving (Open \& Explore) [52].

Raw Data \& Context. As we've demonstrated, insight can be derived from datasets that only speak to $\sim 5 \%$ of the last mile logistics sector. With better data coverage of the last mile and the movements of other vehicles in the city (e.g. cars, public transport, people) more insight can be drawn and used to analyse urban mobility, the requirements of stopping locations, and how peaks in time and space impact congestion and sustainability. As we've highlighted in our case study data cleansing and formatting is a priority to help build confidence in data analysis. Challenges in using such information include dealing with missing and poorly formatted data fields and the sheer volume of data, with around 840,000 records obtained for a 4-month period.

A primary enabler of our analysis is the field work that we've performed to contextualise our understanding of last mile logistics. Qualitative and nuanced descriptions and stories of how a rich socio-technical system such as the last mile are challenging to represent in data hubs and 


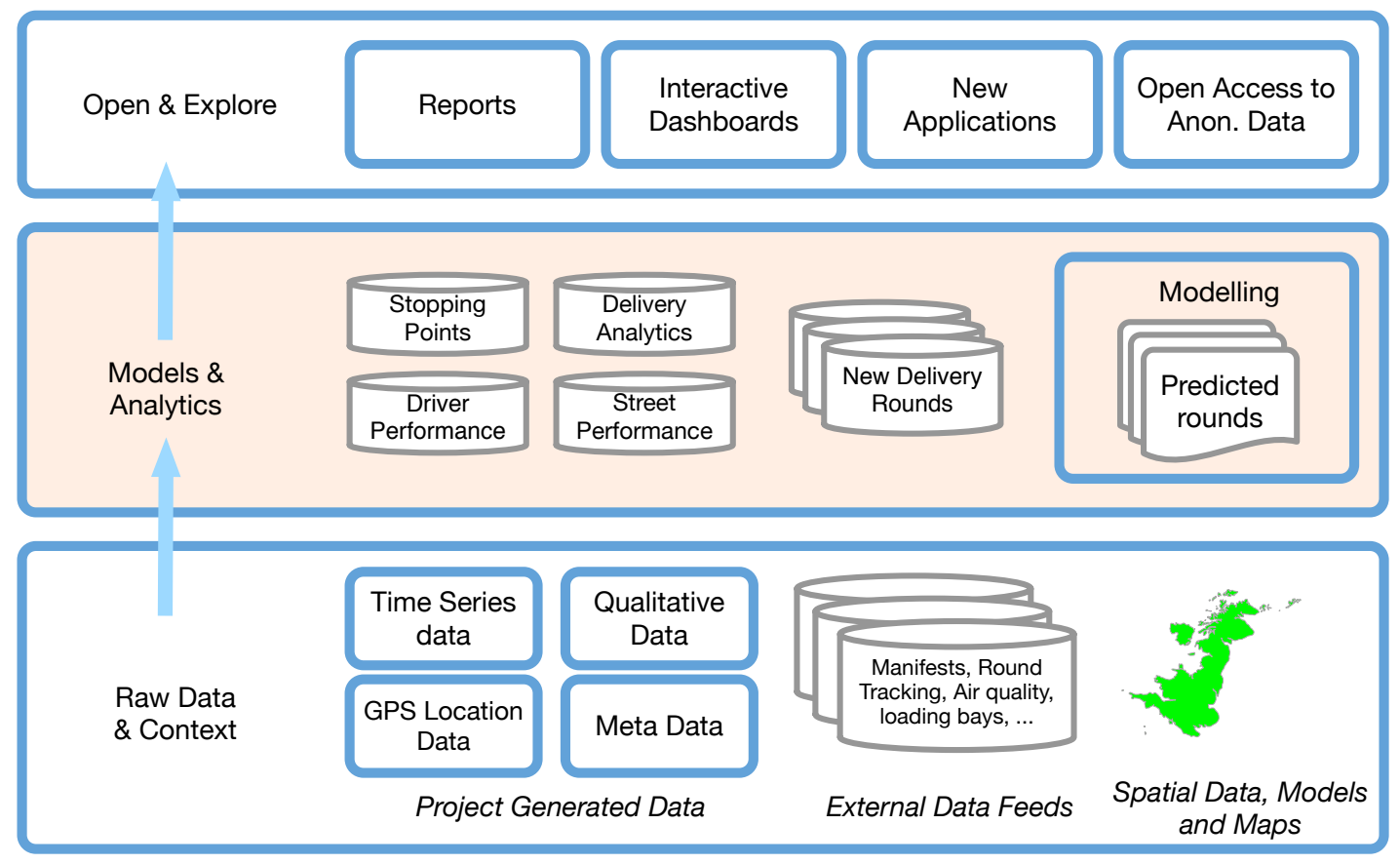

Figure 6: A platform overview for bringing together datas sources and enabling decision support and policy impact on last-mile logistics

repositories but we argue that this context is essential to produce analysis, models and reports that capture the reality of last mile logistics.

Models \& Analytics. As previously discussed, existing work leverages models and analytics to develop understandings of where the appropriate levers are for effecting change in last mile logistics. This layer looks to combine the data and context to help develop models that are better contextualised by the last mile, enabling new understanding of urban street performance and how models (e.g. Agent Based Models) can help demonstrate the impact of policy decisions in urban last mile logistics.

Open \& Explore. Making the data, findings and tools accessible and open (and open source) is important to foster new collaborations and allow for community development. We see that creating APIs and demonstrator dashboards and data visualisations is one way that a conversation can be had with decision makers, policy makers and other key stakeholders. Data standards governing the format and quality of data can support richer integration and insight by bringing business and urban data together, though note that care needs to be taken to protect commercial sensitivities and gain the trust and support of businesses operating in this fiercely competitive commercial sector.

\section{Opportunities: ICT for Sustainable Last Mile Logistics}

Our detailed analyses of parcel carrier operations in central London has suggested how ICT can be an effective tool in the identification of areas where new legislation around kerb usage, policy and industry innovation grounded in understanding spatial and temporal peaks in deliveries can 
be made. Our fieldwork also suggests where new understandings regarding how optimisation of the last mile should incorporate the overlap in express and non-express deliveries, multiple courier services, and driver practices including stopping and walking should be incorporated. From this, we see a number of opportunities where the ICT4S community can help promote more sustainable last mile logistics.

\subsection{Decision support and policy change}

As part of a smarter, more sustainable city, decision makers can make more informed data-driven decisions that promote more sustainable last mile logistics [12]. Decision support tools are a crucial component in the smart sustainable last mile logistics that helps challenge the dominant 'predict and provide' models of urban transport and logistics planning [20]. We see ICT as a key enabler to help overcome the legislative barriers and urban design choices [15], through the use of big data and spatial analytics to realise smart logistics (e.g. [49]) that can help decision makers understand a more holistic view of the impacts of freight on urban environments.

\subsection{Encouraging Collaboration}

The parcel industry is highly competitive on pricing meaning that efficiency is highly important, especially where profit margins can be low [44]. Inherently, there is mutual distrust between rival couriers and parcel carriers driven by fierce competition in the last mile marketplace. This makes collaboration challenging, but not impossible, especially in the contexts where it is cheaper to do so, for example where there is a high premium due to carbon emissions charging areas and vehicle bans [35].

In such an example, it is viable for third parties who offer zero carbon consolidation of parcel deliveries across carriers to exist. One such example is Gnewt Cargo ${ }^{4}$. These kinds of business models are key in helping reduce the financial and environmental cost of deliveries in urban areas. Models such as this one may one of the limited cost effective ways to keep business as usual last mile delivery trends cost effective for consumers. A platform for sustainable logistics should look to help develop neutral third party businesses or areas where restrictive practice mandated by legislation (e.g. emission or congestion charges) can effectively steer the market towards more sustainable solutions.

\subsection{Worker, Customer and Stakeholder Practices}

People (customers), actors (workers and employees), stakeholders (industry and policy), and users (urban citizens and road users) all play a key roles in the socio-technical last mile logistics system. Considering the practices of the stakeholders in last mile logistics system is an essential next step to understand how workers may play a role in making logistics more sustainable (cf. $[24,7])$. Developing new understandings of worker practices based on how they currently optimising their own round can help influence how these lessons can be transferred into the working practices of others, how logistics optimisation is done, considering the human factors of workers in policies and to help create more collaborative and sustainable last mile logistics. This kind of future work can help us understand how 'unattended delivery' options [45] help or hinder last mile deliveries where 'proof of delivery' from a human recipient plays a key role in service level agreements.

\footnotetext{
${ }^{4}$ Gnewt Cargo are an green vehicle delivery fleet whom operate in the ultra low emission zone in central London, delivering parcels for a number of top couriers using a fleet made up of electric vehicles and cargo bikes http://www.gnewtcargo.co.uk (accessed Nov. 2017).
} 


\subsection{Enabling data sharing}

From our experience it's clear that different logistics companies use different systems for their vehicle, parcel and worker tracking. This creates a problem when it comes to doing analysis across datasets as a large amount of time is spent to cleanse and structure the data for analysis. We recommend that a new data standard that support big data analytics is developed, encouraging consistent parameters across datasets and a known format that is easier to structure and interpret. Another issue that arises when working with parcel manifest data is that the data (including names and addresses) is often entered by either a customer or delivery driver and is therefore prone to errors and inaccurate inputs. Given that address data is the primary data source for making decisions about the spatial dimensions of last mile logistics it is imperative that data input is considered more closely in system design and better data cleansing methodologies are developed. We also see creating open data sets (cf. Figure 6) as an essential part of engaging with the ICT4S community to develop design projects and tools for smart cities (cf. [42]).

\subsection{Toward engaging the community}

Changes in inner city regulation and policy is creating an opportunity for 'clean last mile' services by encouraging more sustainable vehicles. A challenge arising from this is rethinking how to do last mile logistics utilising alternative vehicles (e.g. cargo bikes, eBikes). Part of rethinking the last mile requires new understanding of how these vehicles are restricted in terms of the number of parcels that can be moved quickly in cities, alongside how these vehicles impact delivery times and how stopping locations and loading bay need to evolve for new vehicles (e.g. bike racks, secure locations for cargo cycles, charging points). We see this as a gap for computer science to work with policy makers to help understand and design better urban spaces and kerbside civic infrastructure (parking, land use).

In order to effectively understand complexity and change policy, a wide range of skills and expertise are required, including: data scientists to cleanse, standardise and store data; spatial modellers can help map match and develop new visuals and models of last mile logistics and urban mobility; social scientists and HCI researchers are required to contextualise the problem space and design new applications; operational researchers to develop new theoretical models from new data sets; and, data and information communication experts are required to turn data and models into knowledge that policy makers can utilise in the development of new policies for sustainable cities and logistics. Only together, can this army of interdisciplinarians help bring about a substantively changed, cleaner last mile.

\section{Conclusion}

In this paper we have introduced last mile logistics, presenting a contextualised case study of the Christmas rush period (aka 'silly season') to demonstrate how an analytical approach can help support policy makers and businesses to promote more sustainable and lower impact urban freight. We have demonstrated how challenging peak delivery times and spaces can help rethink how last mile logistics is planned and provisioned during peak periods to reduce congestion and air pollution in cities. We have presented our vision of a digital sustainable last mile logistics platform that looks to enable smart and sustainable last mile logistics by blending the academic and industrial strengths of ICT4S. Our vision encourages a multi-disciplinary approach to build a rich and dynamic portrait of sustainable last-mile logistics, enabling collaboration, and 
ICT for Sustainable Last-Mile Logistics: Data, People and Parcels.

Bates et al.

decision support, working to acknowledge socio-technical complexity in order to change policies.

\section{Acknowledgment}

The work forms part of an EPSRC-funded project (EP/N02222X/1) called Freight Traffic Control 2050 (http://www.ftc2050.com/). We extend our sincere gratitude to our industrial partners Gnewt Cargo, TNT, and Transport for London for their continued support.

\section{References}

[1] J. Allen, M. Piecyk, M. Piotrowska, F. McLeod, T. Cherrett, K. Ghali, T. Nguyen, T. Bektas, O. Bates, A. Friday, S. Wise, and M. Austwick. Understanding the impact of e-commerce on last-mile light goods vehicle activity in urban areas: The case of london. Transportation Research Part D: Transport and Environment, 2017.

[2] J. Allen, Maja Piecyk, and Marzena Piotrowska. An analysis of the parcels market and parcel carriers' operations in the UK, 2015. http://www.ftc2050.com/reports/westminster_parcels_ final_Dec_2016.pdf, (accessed, Nov., 2017).

[3] Julian Allen, Tolga Bektas, Tom Cherrett, Adrian Friday, Fraser McLeod, Maja Piecyk, Marzena Piotrowska, and Martin Zaltz Austwick. Enabling the freight traffic controller for collaborative multi-drop urban logistics: practical and theoretical challenges. Transportation Research Board Annual Meeting, 2017.

[4] Yevgeniya Arushanyan, Elisabeth Ekener Petersen, Asa Moberg, and Vlad C Coroama. A framework for sustainability assessment of ICT futures scenarios and sustainability impacts of future ict-societies. Joint Conference on 29th International Conference on Informatics for Environmental Protection/3rd International Conference on ICT for Sustainability (EnviroInfo and ICT4S), SEP 07-09, 2015, Univ Copenhagen, Copenhagen, DENMARK, pages 1-9, 2015.

[5] Oliver Bates, Adrian Friday, Julian Allen, Tom Cherrett, Fraser McLeod, Tolga Bektas, ThuBa Nguyen, Maja Piecyk, Marzena Piotrowska, Sarah Wise, and Nigel Davies. Transforming last-mile logistics: Opportunities for more sustainable deliveries. Proc. CHI'18, 2018.

[6] Oliver Bates, Bran Knowles, and Adrian Friday. Are people the key to enabling collaborative smart logistics? Proceedings of the 2017 CHI Conference Extended Abstracts on Human Factors in Computing Systems, pages 1494-1499, 2017.

[7] Thomas Baudel, Laetitia Dablanc, Penelope Alguiar-Melgarejo, and Jean Ashton. Optimizing urban freight deliveries: from designing and testing a prototype system to addressing real life challenges. Transportation Research Procedia, 12:170-180, 2016.

[8] Jay R. Brown and Alfred L. Guiffrida. Carbon emissions comparison of last mile delivery versus customer pickup. International Journal of Logistics Research and Applications, 17(6):503-521, 2014.

[9] Michael Browne, Julian Allen, and Penny Alexander. Business improvement districts in urban freight sustainability initiatives: A case study approach. Transportation Research Procedia, 12:450$460,2016$.

[10] Michael Browne, Christophe Rizet, and Julian Allen. A comparative assessment of the light goods vehicle fleet and the scope to reduce its $\mathrm{CO}_{2}$ emissions in the UK and France. Procedia-Social and Behavioral Sciences, 125:334-344, 2014.

[11] Robert Bryłka, Krzysztof Kazubski, and Jan Studzinski. ICT system for smart city management. 2nd International Conference on ICT for Sustainability (ICT4S 2014), pages 24-27, 2014.

[12] Gerardo Carpentieri. Smart and sustainable logistics for a competitive europe, 2015. 
ICT for Sustainable Last-Mile Logistics: Data, People and Parcels.

[13] Tom Cherrett, Janet Dickinson, Fraser McLeod, Jason Sit, Gavin Bailey, and Gary Whittle. Logistics impacts of student online shopping-evaluating delivery consolidation to halls of residence. Transportation Research Part C: Emerging Technologies, 78:111-128, 2017.

[14] Consultancy.uk. Parcel delivery sector in a squeeze, say consultants, January 6 2015. http:// www.consultancy.uk/news/1291/parcel-delivery-sector-in-a-squeeze-say-consultants, (accessed, Nov., 2017).

[15] Laetitia Dablanc. Goods transport in large european cities: Difficult to organize, difficult to modernize. Transportation Research Part A: Policy and Practice, 41(3):280-285, 2007.

[16] Department for Transport. Transport Statistics Great Britain 2015, 2015. https://www.gov . uk/government/uploads/system/uploads/attachment_data/file/489894/tsgb-2015.pdf, (accessed, January 2017).

[17] Department for Transport. Transport Statistics Great Britain 2016, 2016. https: //www.gov.uk/government/uploads/system/uploads/attachment_data/file/576113/ tsgb-2016-print-ready-version.pdf, (accessed, January 2017).

[18] C. Dunn. Delivery the key to growing online retail, The Guardian, April 17, 2013, 2013. https: //www.theguardian.com/sustainable-business/delivery-key-growing-online-retail, (accessed, Nov., 2017).

[19] Julia Edwards, Alan McKinnon, and SL Cullinane. Carbon auditing the 'last mile': modelling the environmental impacts of conventional and online non-food shopping. Green Logistics Report, Heriot-Watt University, 2009.

[20] Murray Goulden, Tim Ryley, and Robert Dingwall. Beyond 'predict and provide': UK transport, the growth paradigm and climate change. Transport Policy, 32:139 - 147, 2014.

[21] Andrew Greasley and Anand Assi. Improving "last mile" delivery performance to retailers in hub and spoke distribution systems. Journal of Manufacturing Technology Management, 23(6):794$805,2012$.

[22] Johannes Gruber, Alexander Kihm, and Barbara Lenz. A new vehicle for urban freight? An ex-ante evaluation of electric cargo bikes in courier services. Research in Transportation Business EJ Management, 11:53-62, 2014.

[23] S. Harris. Online shoppers could be banned from accepting parcels at work., 2017. http://www.itv.com/news/london/2017-01-19/ online-shoppers-could-be-banned-from-accepting-parcels-at-work/, (accessed, Nov., 2017).

[24] Greger Henriksson, Anders Gullberg, Mattias Höjer, and Åsa Nyblom. ICT-based sub-practices in sustainable development of city transport. ICT4S, 2014.

[25] Lorenz M Hilty and Jan CT Bieser. Opportunities and risks of digitalization for climate protection in switzerland. 2017.

[26] M. Huschebeck. Espace de Livraison de Proximité. Bordeaux, Etlis: The urban mobility observatory, 2014. http://www.eltis.org/discover/case-studies/ espace-de-livraison-de-proximite-bordeaux, (accessed, Nov. , 2017).

[27] IMRG. UK Consumer Home Delivery Review 2014., 2014. http://p2pmailing.co. uk/wp-content/uploads/2014/11/IMRG-UK-Consumer-Home-report-2104.pdf, (accessed, Nov., 2017).

[28] IMRG. MetaPack UK Delivery Index Report, September 2015, 2015. https: //www . metapack.com/ wp-content/uploads/2015/10/MetaPack-September-2015-Delivery-Index-August-2015.pdf, (accessed; January, 2017).

[29] IMRG. MetaPack UK Delivery Index Report, April 2017., 2017. https://www.metapack.com/ wp-content/uploads/2017/04/April-2017-Delivery-Index-March-2017.pdf, (accessed, Nov., 2017).

[30] T. F. Jensen. Viewpoint from UPS (presentation 21812). Transportation Research Board 96th Annual Meeting, Washington D.C., 8-12 January, 2017. 
[31] Anna Kramers, Mattias Höjer, Nina Lövehagen, Josefin Wangel, and E Ab. ICT for sustainable cities: How ICT can support an environmentally sustainable development in cities. ICT4S 2013: Proceedings of the First International Conference on Information and Communication Technologies for Sustainability, ETH Zurich, pages 183-188, 2013.

[32] Anna Kramers, Josefin Wangel, and Mattias Höjer. Governing the smart sustainable city: The case of the Stockholm Royal Seaport. ICT4S, ICT for Sustainability, 2016, Amsterdam, 2016.

[33] E. Manning. Why retailers stop selling online: the hidden cost of e-commerce, The Guardian, December 15 2016. https://www.theguardian.com/small-business-network/2016/dec/15/ hidden-cost-e-commerce-online-shopping-entrepreneurs, (accessed, Nov., 2017).

[34] Alessio Mastrucci, Emil Popovici, Antonino Marvuglia, Luís De Sousa, Enrico Benetto, and Ulrich Leopold. Gis-based life cycle assessment of urban building stocks retrofitting-a bottom-up framework applied to luxembourg. EnviroInfo and ICT for Sustainability 2015, 2015.

[35] Matt McGrath. Four major cities move to ban diesel vehicles by 2025, BBC, 2016. http://www . bbc.co.uk/news/science-environment-38170794, (accessed, January, 2017).

[36] Mintel. Mintel (2016) Online Retailing - UK, July, 2016.

[37] R. Neate. Sports Direct challenged by MPs over claims it underpays couriers, The Guardian, September 14 2017. https://www.theguardian.com/business/2017/sep/14/ sports-direct-challenged-by-mps-over-claims-it-underpays-couriers?CMP=Share_ iOSApp_Other, (accessed, Nov., 2017).

[38] Roberto Nocerino, Alberto Colorni, Federico Lia, and Alessandro Luè. E-bikes and e-scooters for smart logistics: environmental and economic sustainability in pro-e-bike italian pilots. Transportation Research Procedia, 14:2362-2371, 2016.

[39] S. O'Conner. UK tries to tackle 'gig economy' conundrum, Financial Times, July 11, 2017, 2017. https://www.ft.com/content/cdd95ffa-664a-11e7-9a66-93fb352ba1fe, (accessed, Nov., 2017).

[40] Ofcom. Annual Monitoring Update on the Postal Market: Financial Year 2014-15, 2015.

[41] Office for National Statistics (ONS). Retail sales index - internet sales, ONS , 2016.

[42] Lucas Pereira, Filipe Quintal, Rodolfo Gonçalves, and Nuno Jardim Nunes. SustData: A Public Dataset for ICT4S Electric Energy Research. ICT4S, 2014.

[43] H. Pink. Virtual loading bays aim to reduce PCNs and boost uptake of cleaner freight vehicles., 2017. http://freightinthecity.com/2017/04/ virtual-loading-bays-aim-reduce-pcns-boost-uptake-cleaner-freight-vehicles/, (accessed, Nov., 2017).

[44] M Pooler. Online orders boost UK parcel market, Financial Times, Jan 5, 2016, 2017. https: //www.ft.com/content/85c03ea8-b3ab-11e5-b147-e5e5bba42e51, (accessed, January, 2017).

[45] Mikko Punakivi, Hannu Yrjölä, and Jan Holmström. Solving the last mile issue: reception box or delivery box? International Journal of Physical Distribution 85 Logistics Management, 31(6):427439, 2001.

[46] Tina Ringenson and Mattias Höjer. Smart city planning and environmental aspects: Lessons from seven cities. ICT for Sustainability 2016, 2016.

[47] M Börjesson Rivera, E Eriksson, and J Wangel. ICT practices in smart sustainable cities: in the intersection of technological solutions and practices of everyday life. 29th International Conference on Informatics for Environmental Protection and 3rd International Conference on ICT for Sustainability, pages 317-324, 2015.

[48] Royal Mail. Full Prospectus, Royal Mail (data taken from Triangle Management Services/Royal Mail Group Fulfilment Market Measure, 2013), 2013.

[49] Hossein Shahrokni, Bram Van der Heijde, David Lazarevic, and Nils Brandt. Big data GIS analytics towards efficient waste management in Stockholm. Proceedings of the 2014 conference ICT for Sustainability, pages 140-147, 2014. 
[50] David Stefan and Emmanuel Letier. Supporting sustainability decisions in large organisations. ICT $4 S, 2014$.

[51] Vanessa Thomas, Christian Remy, Mike Hazas, and Oliver Bates. HCI and Environmental Public

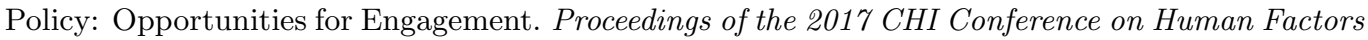
in Computing Systems, pages 6986-6992, 2017.

[52] Jack H Townsend. Digital taxonomy for sustainability. ICT for Sustainability 2015, 2015.

[53] Transport for London. Regent Street Delivery and Servicing Regent Street Site Survey, August 2009, reported prepared by Ove Arup and Partners, Transport for London, 2009.

[54] Transport for London. Travel in London: Report 8, 2015. https://tfl.gov.uk/cdn/static/cms/ documents/travel-in-london-report-8.pdf, (accessed, January, 2017).

[55] J. Twentyman. Delivery charges cost online retailers dear, Financial Times, November 18, 2015, 2015. https://www.ft.com/content/fd88f556-70bc-11e5-9b9e-690fdae72044, (accessed, Nov., 2017).

[56] Johan Visser, Toshinori Nemoto, and Michael Browne. Home delivery and the impacts on urban freight transport: A review. Procedia-social and behavioral sciences, 125:15-27, 2014.

[57] West End Partnership. Deliveries \& Servicing Group Meeting Minutes. 13 January 2017. https://crossriverpartnership.org/media/2017/02/WEP-Meeting-Minutes-13.1.17.pdf (accessed Nov. 2017), 2017.

[58] Work and Pensions Committee. Self-employment and the gig economy inquiry, 2017, 2017. https://www.parliament.uk/business/committees/committees-a-z/ commons-select/work-and-pensions-committee/inquiries/parliament-2015/ self-employment-gig-economy-16-17/, (accessed, Nov. 2017).

[59] WWF. The potential global $\mathrm{CO}_{2}$ reductions from ICT use: Identifying and assessing the opportunities to reduce the first billion tonnes of $\mathrm{CO}_{2} .2008$.

[60] Alberto M. Zanni and Abigail L. Bristow. Emissions of $\mathrm{CO}_{2}$ from road freight transport in London: Trends and policies for long run reductions. Energy Policy, 38(4):1774 - 1786, 2010. Energy Security - Concepts and Indicators with regular papers.

[61] Jorge Luis Zapico. Blinded by data: The risks of the implicit focus on data in ICT for Sustainability. 2nd International Conference on ICT for Sustainability (ICTS), AUG 24-27, 2014, Stockholm, SWEDEN, pages 148-154, 2014. 